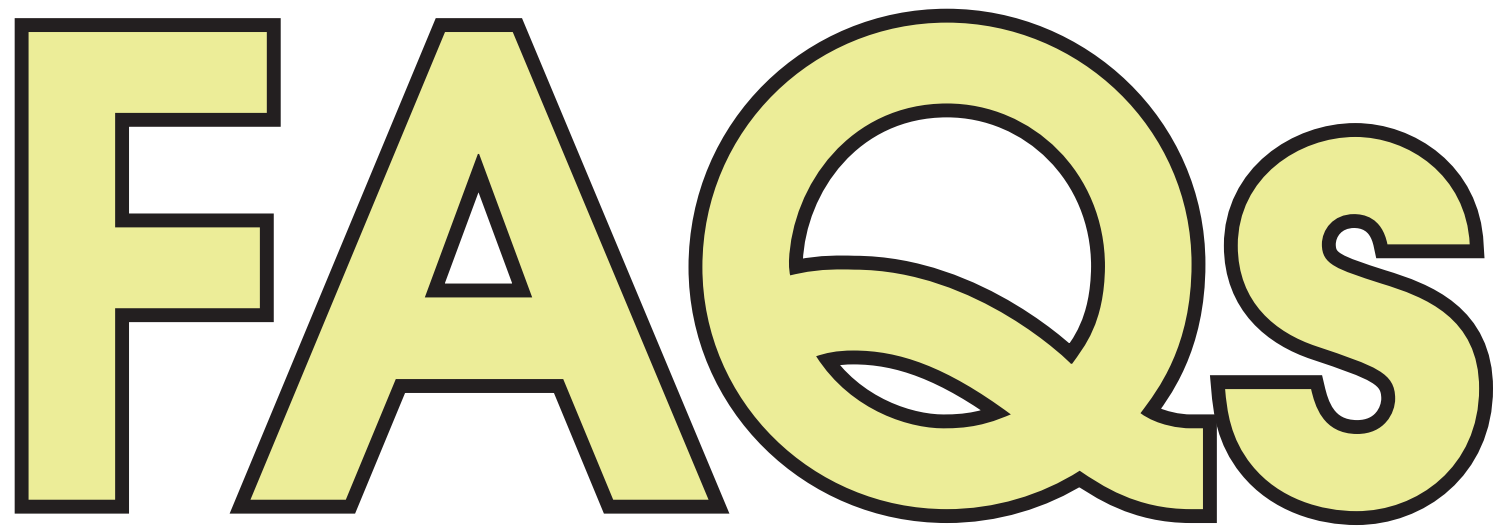

\title{
for dental teams
}

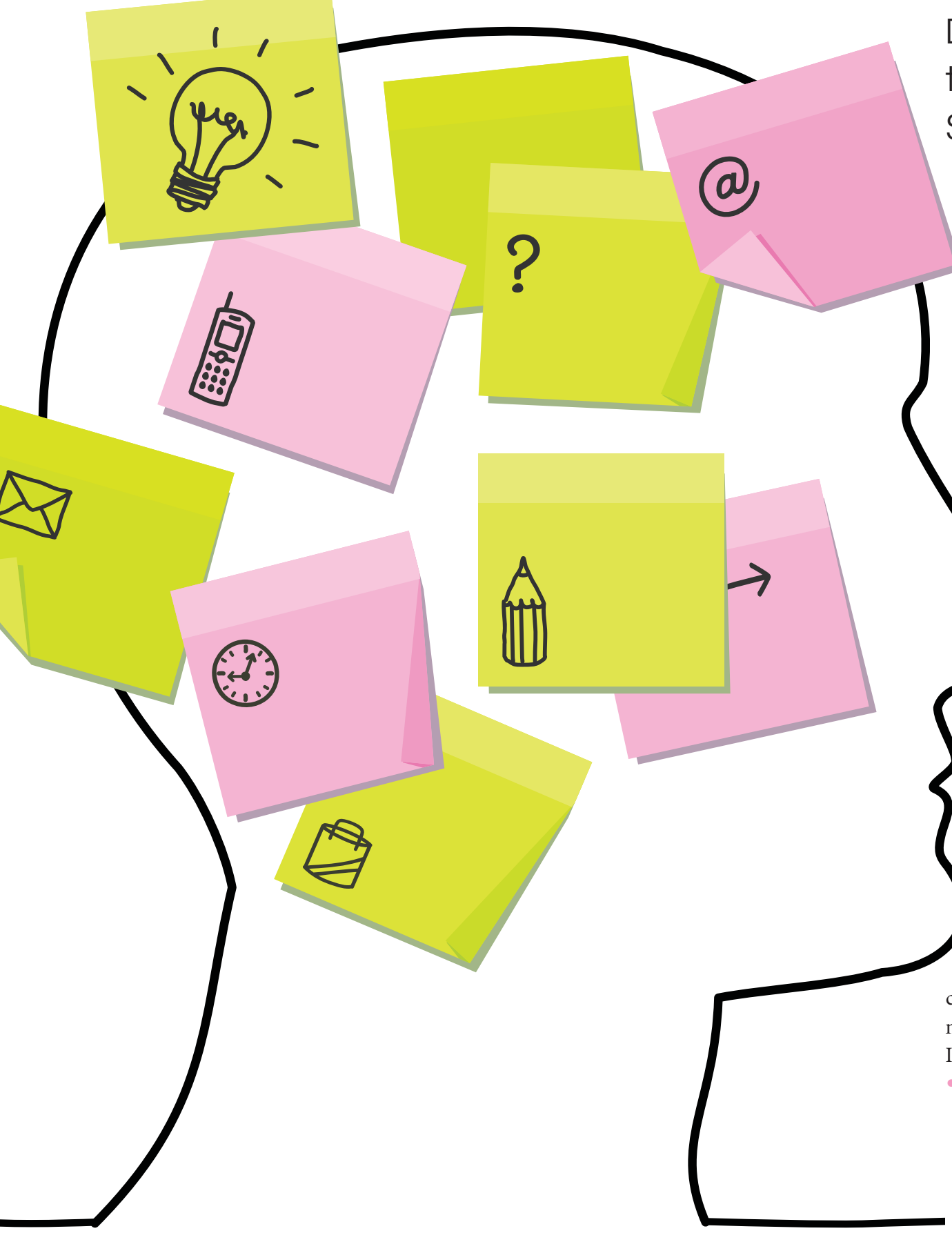

It is every registered DCP's responsibility to apply the GDC's Standards guidance ${ }^{1}$ to their work. Here are the answers to some frequently asked questions to help you out, provided by the GDC.

\section{. Can I work as a dental nurse} while I am in training, and if so, are there any requirements before I start work?

Dental nurses who are employed by a practice and enrolled on a training course leading to registration which has yet to start can be defined as in training'.

Dental nurses who are employed by a practice with a view to enrolling on a training course for which enrolment has not yet opened can also be defined as 'in training.

Dental nurses who have passed their National Certificate examination but are still undertaking the 24 months' chairside experience required for full qualification are considered 'in training' and as student dental nurses until they receive their qualification. In these cases:

- Before the student dental nurse undertakes any duties in the practice he or she must receive an appropriate induction, which must include confidentiality and health and safety in the practice 
- The student dental nurse must keep a log book of the training they receive in the practice

- The student dental nurse must not undertake exposure prone procedures, including cleaning instruments, until they have received their appropriate vaccinations as required where they practise.

A named supervising registrant must take responsibility for supervising a dental nurse in training. By undertaking this responsibility, the supervising registrant agrees to be accountable for the work of the student dental nurse.

Wherever the GDC standards refer to a dental nurse, that includes a dental nurse in training.

\section{Can I work as a dental technician while I am in training to be a dental technician, and if so, are there any requirements before I start work?}

Technicians who are employed by a laboratory or practice and enrolled on a training course leading to registration which has yet to start can be defined as 'in training'.

Technicians who are employed by a laboratory or practice with a view to enrolling on a training course for which enrolment has not yet opened can also be defined as in training. In both these cases:

- Before the student dental technician undertakes any duties in the laboratory or practice they must receive an appropriate induction, which must include confidentiality and health and safety in the practice and immunisation (if appropriate, eg in a clinical setting)

- The student dental technician must keep a $\log$ book of the training they receive in the laboratory or practice.

A named supervising registrant must take responsibility for supervising a dental technician in training.

By undertaking this responsibility, the supervising registrant agrees to be accountable for the work of the student dental technician.

Wherever GDC standards refer to a dental technician, that includes a dental technician in training.

\section{Can student dental professionals act as dentall nurses?}

Student dental professionals may act as a dental nurse provided they:

- Have reached an appropriate point in their own training

- Satisfy the health and vaccination requirements specified for a 'dental nurse in training'
- Have undertaken at least the equivalent of the trainee dental nurse's induction

- Work under the supervision of an appropriate named registrant.

The supervising registrant must take responsibility for ensuring that student dental professional is a current student and for determining that the student dental professional has reached an appropriate level in their training.

\section{When supervising a dental nurse, technician or other student dental professional in training, what guidance do I need to provide them with?}

Make sure that trainees and other unregistered members of the team working with you or under your supervision are familiar with Standards for dental professionals guidance, ${ }^{1}$ and follow it.

\section{Who can provide GDC registrants with dental nursing support?}

GDC registrants should only receive dental nursing support from registered dental nurses.

\section{What should registrants do in circumstances where they don't have assistance from a dental nurse?}

Registrants seeing patients should routinely be assisted by a dental nurse.

Practices should have standby arrangements which can be activated at short notice, such as a relationship with an agency providing registered staff, to cover absences caused by leave, sickness or training.

If no dental nursing assistance is available, the registrant should act in the best interests of the patient when deciding whether to proceed with treatment.

If it is in the best interests of the patient to go ahead, the registrant must ensure that there is a third person present who has been told what their role would be in a medical emergency.

The third person must not work in the patient's mouth or otherwise act as a dental nurse.

\section{What guidance does the GDC have for registrants offering non-surgical cosmetic procedures?}

Registrants choosing to offer Botox or other non-surgical cosmetic procedures should note that the GDC expects the same high standards of them, whatever the type of treatment they are carrying out.

In particular, they are advised to work within their knowledge and professional competence and be prepared to back up the decisions they make.
Careful thought also needs to be given to maintaining professional standards in relation to advertising these services, and to the need to be indemnified for them.

\section{What are the responsibilities of} registrants commissioning and manufacturing dental appliances?

All GDC registrants involved in prescribing, manufacturing and fitting dental appliances have a role to play in protecting patients from harm and in providing a safe and effective standard of care, and must comply with the GDC standards guidance.

With regards to the commissioning and manufacturing of dental appliances, principles 4.7 to 4.9 are particularly relevant.

These overriding principles are complemented by the following standards of practice.

\section{Do registrants manufacturing dental appliances need to follow any legal requirements?}

If you make a dental appliance, you must understand and comply with your legal responsibilities as 'manufacturer' under the Medical Devices Directive.

These are legal requirements rather than GDC rules and the GDC expects you to fulfil these responsibilities and will hold you accountable for doing so.

\section{What responsibilities do registrants have if they arrange for a dental appliance to be made in the UK?} If you arrange for dental appliances to be made in the UK, you are responsible for issuing the prescription to and receiving the appliance from a UK-registered dental technician.

If you prescribe a dental appliance to be made by a person in the UK who is not a registered dental technician you are liable to face a GDC fitness to practise inquiry.

Equally, you are liable to face a GDC fitness to practise inquiry in you receive a dental appliance made in the UK by a person who is not a registered dental technician.

\section{What responsibilities do registrants have if they sub-contract or prescribe dental appliances to be made outside the UK? \\ When making the decision to either sub-con- tract the manufacture of a dental appliance, or use a dental laboratory or agent which sources dental appliances outside the UK, your choice not to use a UK-registered dental technician puts a particular responsibility on you. \\ You will be held professionally accountable for the safety and quality of the appliance. \\ This is because you have chosen not to}


sub-contract or issue the prescription to a registered dental technician who would otherwise be personally accountable.

You take on the dental technician's responsibilities for the appliance and the GDC will hold you accountable for your decision.

Further, the GDC expects you to have taken appropriate steps to discharge the extra responsibilities you choose to accept when you make this decision.

\section{Who can carry out initial assessments of patients?}

Patients should be seen by a dentist before being treated by other members of the dental team.

The only exceptions to this are that clinical dental technicians can provide sports mouthguards direct to the public and can supply and maintain full dentures for patients with no natural teeth.

\section{Can a patient take a treatment plan to another dental professional?} Yes. When a dentist provides the treatment plan for a patient, the patient may take the treatment plan to any appropriate registered dental professional who can, within their skills and limits of the plan, provide treatment and make any further appropriate referrals.

\section{'All tooth whitening}

\section{procedures, including}

\section{bleach and laser}

\section{treatment, are seen as}

\section{the practice of dentistry}

\section{by the GDC.}

\section{Do registrants have to comply with any other guidance apart from the GDC guidance?}

Registrants have legal obligations in a number of areas because they are dental professionals.

The GDC expects registrants to understand and comply with these obligations and reserves the right to deal with potential breaches which are brought to their attention, even if they have not been the subject of action by another agency.

Registrants must be sure that they understand and comply with their obligations under legislation in relation to:

- Disposal of clinical and other

hazardous waste

- Employment

- Health and safety

- Indemnity

- Ionising radiation regulations

- Medical devices directive

- Protecting children and vulnerable adults.

\section{Is tooth whitening the practice} of dentistry?

It is the GDC's view that applying materials and carrying out procedures designed to improve the aesthetic appearance of teeth amounts to the practice of dentistry and is therefore limited to GDC registrants.

Therefore all tooth whitening procedures, including bleach and laser treatment, are seen as the practice of dentistry by the GDC.

The carrying out of dentistry by non-registrants is a criminal offence and the Council will prosecute any persons undertaking this activity in appropriate cases.

\section{Which GDC registrants can undertake tooth whitening?}

Until recently, it was the Council's position that only dentists could undertake tooth whitening.

At the Council meeting in June 2008, it was decided that in addition to dentists being able to carry out tooth whitening, dental hygienists and dental therapists can carry out tooth whitening on the prescription of a dentist as an additional skill.

It has also been decided that dental nurses can, as an additional skill, take impressions and make bleaching trays to a dentist's prescription.

\section{Is there particular guidance to bear in mind when providing tooth whitening?}

They key ethical issues that may arise are:

- Act in the best interests of the patient in providing a high standard of care

- Obtain consent for treatment, which you must be competent to carry out

- Obtain a medical history of the patient before starting treatment

- Give necessary explanations about benefits and risks.

These and similar issues can arise in connection with any dental treatment proposed or carried out, including treatment designed to improve the appearance such as tooth whitening.

They apply whether the registrant personally delivers the treatment or gives advice to patients about the use of home kits.

It is open to patients to complain to the
GDC about these matters, as with any form of care or treatment.

\section{Does my indemnity cover tooth whitening?}

Registrants must always check with their defence organisation or other indemnity provider, because different organisations have different rules and policies.

Do not assume that you will be covered in respect of the use of controversial bleaching products.

If you practise in any field without appropriate indemnity arrangements, your registration will be at risk.

\section{Do I have to attend a course to obtain 'additional skills' described in the 'Scope of practice"?}

Training can consist of either going on a course or receiving in-house training.

However, it is up to the individual registrant to be sure that they are competent and to be able to demonstrate why they believe that to be the case.

A course will usually provide some sort of certificate if you complete it successfully. So, if you learn a new skill in-house, it is important to keep a log.

This log is a record of your training which illustrates your competency if you ever need to justify yourself to the GDC.

\section{What does it mean to be "trained and competent"?}

The best way to approach the concept of 'trained and competent' is to ask yourself: 'If a complaint was made against me, how can I justify that I am trained and competent to carry out this particular additional skill?'

If you cannot confidently provide evidence to demonstrate that you are trained and competent, you should think about whether you need more training or whether you could find some way to demonstrate your competence.

\section{As a dental care professional, what type of impressions can I take? \\ The GDC does not specify types of impressions.}

DCPs are able to take impressions to the prescription of a dentist as long as they are fully trained and competent.

1. General Dental Council. Standards for dental professionals. 2005. Available at www.gdc-uk.org

To contact the General Dental Council's Customer Advice and Information Team, telephone 08452224141 (local rate). Also see www.gdc-uk.org 